\title{
'Not rocket science': managing STIs in the integrated care setting of UK general practice
}

Integrated sexual health and family planning services can be provided within primary care with only minor modifications to service configuration. However, only a very small percentage of general practices currently offer an enhanced sexual health service. Most GUM clinics do not provide contraceptive services and contraceptive services do not provide comprehensive STI diagnosis and management. General practices are uniquely placed to offer an effective integrated service and reduce the pressure on sexual health clinics. Funding this service in primary care offers a good and accessible service to patients and a considerable saving for commissioners. In this article, we provide practical suggestions on offering an enhanced sexual health service as informed by our experience in setting up this service at the James Wigg Practice, a large GP practice in Camden, London.

\section{PLANNING}

While setting up the service, we endeavoured to follow the 'Recommended Standards for Sexual Health Services'. 'We set out to achieve the goal of integrated sexual health, family planning and general medical care with reference to the Department of Health document Competencies for Providing More Specialised Sexually Transmitted Infection Services Within Primary Care. ${ }^{2}$

We did this by analysing current services and identifying service development and equipment needs, developing protocols applicable to primary care, undertaking clinical and wider team training, and launching a programme of sexual health promotion and education including chlamydia screening (Boxes 1-3). Users are allowed greater choice through improved access to service provision and early, quick detection and management of STIs combined with easy access to contraceptive services, in addition to coordination between ourselves and secondary care services. ${ }^{1}$

\section{Access}

We made a policy decision to integrate sexual health consultations into routine surgeries, rather than providing a standalone service. Clients book a routine appointment and need not inform reception of their intended reason for attendance. Patients may see a doctor, nurse practitioner, or nurse for an initial appointment. Complex cases are referred or advice is sought from secondary health care services.

This approach reduces the stigma of sexual health consultations and makes the service more accessible and sustainable.

Studies of patients' reasons for preferring sexual health consultations in general practice include continuity of care, knowledge of medical history, ease of access, and ability to see a female doctor if required. ${ }^{3}$ The disadvantages of providing this service in primary care include some clients having to pay a prescription charge for antibiotics and shorter consultation times. Certain groups, including young men and African individuals in particular, have expressed a distrust for general practice confidentiality. ${ }^{3}$ Despite the nonidentifiable service provision we have found that some groups, particularly gay men, rarely access our service. This is in keeping with the findings of a Department of Health document which showed that gay men maintain a strong preference for stand-alone specialist services. ${ }^{3}$

\section{HIV SCREENING ISSUES}

The Chief Medical Officer released a statement in September 2007 expressing concern at the rising number of people living with HIV in the UK, as well as the significantly worsened prognosis in those whose diagnosis is delayed. Given the advances in the treatment of HIV, it should be considered a long-term and manageable illness. It emphasised that lengthy pre-test discussion is not required unless a patient needs or requests this. ${ }^{4}$ Clear guidance is given by the $U K$ National Guidelines for HIV Testing. ${ }^{5}$ Aiming to reduce the stigma associated with HIV and increase uptake of testing,

\section{Box 1. Services needed for implementing an integrated comprehensive sexual health service in primary care.}

Routine services (provided by most GP practices)

Taking sexual histories

Investigating symptomatic females

Chlamydia screening information

\begin{tabular}{ll} 
HIV information and referral for testing & $\begin{array}{l}\text { the National Chlamydia Screening } \\
\text { Programme) }\end{array}$ \\
\hline Contraceptive information and services & HIV advice and testing \\
\hline Hepatitis B immunisation & IUD and other LARC methods provision \\
\hline Cervical cytology & \\
\hline $\begin{array}{l}\text { Referring worried well and positive cases } \\
\text { if identified }\end{array}$ & $\begin{array}{l}\text { Diagnosis and treatment of chlamydia, } \\
\text { gonorrhoea, herpes, and genital warts }\end{array}$ \\
\hline & Partner notification \\
\hline
\end{tabular}


we try to normalise HIV testing within our everyday practice. For the most part, we consent patients rather than counsel them prior to HIV testing and negative HIV results are given over the phone by reception staff via our dedicated results line. However, if a person is considered high risk, more time is dedicated to pretest counselling.

\section{Managing results}

At our practice, the process for dealing with STI results dovetails with our overall system for all results. Symptomatic patients are booked for a follow-up appointment. Asymptomatic patients are informed at their initial appointment to phone the surgery for their results 7 days following testing, thus giving the doctor an opportunity to arrange an appointment, if needed, well before this time. If a positive result is received, the patient is phoned by the doctor and given an appointment within 48 hours. At this appointment, management and partner notification are discussed as well as general sexual health counselling. Cases of HIV, syphilis, hepatitis, and complicated STIs are referred to secondary care.

\section{Finance}

The cost of a sexual health consultation in general practice is much less than an equivalent consultation in a GUM clinic and, thus, funding this service in primary care represents a significant saving for PCTs. ${ }^{3}$ In a study which examined the cost of treating an STI in general practice in City and Hackney, the cost to the PCT per case of gonorrheal or chlamydial infection diagnosed within the local enhanced service was significantly less than those cases diagnosed in a GUM clinic. ${ }^{6}$

The Quality and Outcomes Framework does not currently provide an incentive to GPs to provide non-essential sexual health services ${ }^{7}$ although LARC education

\section{Box 2. Equipment needed for implementing a comprehensive sexual health service in primary care.}

\begin{tabular}{lll}
$\begin{array}{l}\text { Equipment most practices } \\
\text { provide/stock }\end{array}$ & $\begin{array}{l}\text { Additional equipment } \\
\text { needed }\end{array}$ & $\begin{array}{l}\text { Equipment to consider } \\
\text { providing }\end{array}$ \\
\hline $\begin{array}{l}\text { Swabs for chlamydia and } \\
\text { gonorrhoea }\end{array}$ & $\begin{array}{l}\text { Viral transport medium } \\
\text { for herpes diagnosis }\end{array}$ & $\begin{array}{l}\text { Microscopy: (expertise } \\
\text { needed; not cost effective; } \\
\text { does not significantly improve } \\
\text { level of care) }\end{array}$ \\
\hline $\begin{array}{l}\text { Blood tests for syphilis, } \\
\text { hepatitis and HIV }\end{array}$ & $\begin{array}{l}\text { Narrow swabs for urethral } \\
\text { gonococcal culture }\end{array}$ & $\begin{array}{l}\text { Cryotherapy for genital warts: } \\
\text { (patient administered } \\
\text { treatment is as effective } \\
\text { although more prolonged) }\end{array}$ \\
\hline $\begin{array}{l}\text { Information leaflets with } \\
\text { details of local sexual health } \\
\text { clinics }\end{array}$ & $\begin{array}{l}\text { Chlamydia screening packs } \\
\text { (urine and self-taken swabs) }\end{array}$ & \\
\hline \multicolumn{3}{l}{} \\
& $\begin{array}{l}\text { Proctoscopes (although blind } \\
\text { rectal swabbing may be }\end{array}$ & \\
& satisfactory if asymptomatic) & \\
\hline
\end{tabular}

has been included in the QOF for 2009/2010. ${ }^{8}$ Although there is a recommended national tariff (including a retainer fee and a item of service payment) for general practices providing
STI services as a national enhanced service, ${ }^{9}$ many PCTs, including our own PCT (Camden) commission these services as a local enhanced service. This adaptation has allowed some PCTs to

\section{Box 3. Activities needed for implementing an integrated comprehensive sexual health service in primary care.}

Protocols/guidelines

- Guidelines for men and women created by adapting local GUM clinic pathways.

- Standardised guidelines easily accessible to all staff on practice intranet.

- Links made with local sexual health specialists to discuss adaptations to pathways and to keep up to date.

Training

- Interested clinical staff given the opportunity to attend STIF course (2-day sexual health training course).

- Staff encouraged to have a 1-2 day attachment at local sexual health clinic.

- Regular educational training sessions within the practice.

Medical Records

- Computer template created to guide health professionals through key questions in sexual health history as well as ensuring systematic recording of key data and coding.

- Data on STIs fully integrated into common medical record with common high standards of retrievability and confidentiality.

Health Education and Promotion

- Enquiries about sexual health and risk exposure normalised as part of routine consultations.

- Sexual health education, family planning advice, and condoms offered and provided.

- Services advertised in practice leaflet and newsletter and in waiting room.

- Services included in information about practice in local publications and newspapers. 
provide this service at a significantly lower cost and practices need to evaluate the cost-benefit of providing these services quite carefully. In Camden both positive results and negative screens are remunerated with a maximum ratio of positive to negatives of $8: 1$. There is a cap on the total amount for this service paid per annum by the PCT, with adjustment of the price for negative screens to remain within this cap. General practices also need to be aware that finance for STI services are included in PCTs' baseline budgets, which allows them the option to divert this money to other local priorities.

The original new GMS specification for a Sexual Health NES provides for commissioned practices seeing patients from other practices not providing an enhanced service. $^{9} \quad$ Locally-agreed protocols and standards need to be agreed in order to enable this service. Processes also need to be agreed whereby non-registered patients are able to access services within a provider practice. Monitoring, reporting and payment for such arrangements can present considerable barriers in practice.

\section{Audit and monitoring}

STI diagnosis and management in general practice are not routinely audited nationally. However within our own PCT practices are both required to submit quarterly reports of activity in order to generate payment and expected to fulfil certain criteria to qualify to provide the service.

\section{CONCLUSION}

We believe the debate about whether GPs should provide management (including diagnosis, treatment, and partner notification) of STIs should come to an end. The advantages of delivering these services, integrated with family planning and within a holistic care setting, are clear. There is no doubt that GP practices can provide these services safely, confidentially, and cost-effectively. The main issues that need to be resolved are those of funding, training, and coordination and support from secondary care providers

\section{Justin Sacks and Elizabeth Goodburn}

\section{REFERENCES}

1. Department of Health, Medical Foundation for AIDS and Sexual Health. Recommended standards for sexual health services.

http://www.dh.gov.uk/en/Publicationsandstatistics/Pu blications/PublicationsPolicyAndGuidance/DH_4106 273 (accessed 4 Nov 2009).

2. Department of Health. Competencies for providing more specialised sexually transmitted infection services within primary care - Assessment Toolkit.

http://www.dh.gov.uk/en/Publicationsandstatistics/Pu blications/PublicationsPolicyAndGuidance/DH_4139 358 (accessed 4 Nov 2009).

3. Department of Health. Evaluation of one-stop shop (OSS) models of sexual health provision. http://www.dh.gov.uk/en/Publicationsandstatistics/Pu blications/PublicationsStatistics/DH_083200 (accessed 4 Nov 2009).

4. Department of health. Donaldson L. Improving the detection and diagnosis of HIV in non-HIV specialities including primary care. Statement of Chief Medical Officer for England, 13 Sep 2007.

http://www.dh.gov.uk/dr_consum_dh/groups/dh_dig italassets/@dh/@en/documents/digitalasset/dh_08233 8.pdf (accessed 9 Nov 2009).

5. British HIV Association, British Association of Sexual Health and HIV, British Infection Society. UK national guidelines for HIV testing. http://www.britishinfectionsociety.org/drupal/sites/de fault/files/GlinesHIVTest08.pdf (accessed 4 Nov 2009).

6. Sohal H, Creighton S, Figueroa J, Gibb A. The impact of establishing a local-enhanced service for treating sexually transmitted infections in primary care. Sex Trans Inf 2008; 84: 235-238.

7. Mann S, Wilkinson C. Reviewing the national sexual health and HIV strategy. J Fam Plann Reprod Health Care 2008; 34(4): 211-212.

8. NHS Employers, BMA. Quality and Outcomes Framework guidance for GMS contract. Delivering investment in general practice. http://www.bma.org.uk/images/qof0309_tcm41184025.pdf (accessed 9 Nov 2009).

9. The NHS Confederation, BMA. National Enhanced Service. More specialised sexual health services. http://www.dh.gov.uk/prod_consum_dh/groups/dh_ digitalassets/@dh/@en/documents/digitalasset/dh_40 78903.pdf (accessed 16 Nov 2009).

DOI 10.3399/bjgp09X473277 